\title{
Effects of awareness programme on the knowledge, attitude and practice of gender preference \& pre-natal sex determination in population of Nasik district
}

\author{
Tawri $\mathbf{P}^{1}$, Patole $\mathbf{K}^{2}$ \\ ${ }^{1}$ Dr Pratik Tawri, Intern, ${ }^{2}$ Dr Kiran Patole, Prof \& HOD, Department of Obstetrics and Gynaecology, both authors are \\ affiliated with MVP's Dr Vasantrao Pawar Medical College, Hospital \& Research Centre, Nashik, Maharashtra, India.
}

Address for Correspondence: Dr Pratik Tawri, Email: tawripratik@gmail.com

\begin{abstract}
Introduction: India is facing a demographic nightmare in terms of gender imbalance, The worrying fact is the child sex ratio in Nashik district is 890 which is much lower than the national average of 919 . This rate of decline is alarming. Though government has implemented PC \& PNDT Act to prevent pre-natal sex determination, it seems not to be reflected in practice. Aims \& Objectives: To assess effect of awareness programme on the Knowledge, Attitude and Practice of Gender Preference \& Pre-natal sex determination in population of Nashik district. Materials and methods: A cross-sectional study was carried out in the antenatal ward of a tertiary care hospital, Nashik district. A total of 100 women were included and a pre-designed and pre-tested questionnaire was used. They were asked regarding the knowledge and attitude towards the PNDT Act. There was Awareness session on PC\&PNDT act and Sex Ratio, post which the questionnaire was given again. Data was analyzed by using Statistical Package of Social Sciences (SPSS) v.22.0. Results: In the Present Study, knowledge regarding PC \& PNDT act was known by $88 \%$ participants. Gender preference of a particular sex in families was $45 \%$ which came down to $12 \%$ during the post awareness. Their desire to know gender of foetus came down to $4 \%$ from $15 \%$ after the awareness programme. Conclusion: The existence of son preference is at an alarming high rate in our society and is the most important - the root cause of imbalanced sex ratio. Thus apart from the legislative measures, people also needs to be educated about the ethical issues related to female foeticide
\end{abstract}

Keywords: Awareness, Attitude, Gender Preference, PC \& PNDT Act, Sex Ratio, Female foeticide

\section{Introduction}

The saying goes like: 'Female foeticide has increased, Female: Male Ratio has decreased, The whole ecological system will be hampered, If the girl child is left to die unpampered'. The increase in female foeticide has seen a proportionate decrease in the sex ratio which has hit an all time low, especially in the $0-6$ age group and if this decline is not checked, the very delicate equilibrium of nature will be permanently destroyed.

The sex ratio is calculated as the number of males per one hundred females in a population globally, whereas in India it is defined as number of females per thousand males [1]. India is one of the few countries in the world which has not shown an improvement in the sex ratio over decades. Sex ratio has been declining in India since 1901[2]. According to Census of India 2014, the sex ratio is very low i.e. 940 females / 1000 males and the child sex

Manuscript received: $4^{\text {th }}$ March 2017

Reviewed: $14^{\text {th }}$ March 2017

Author Corrected: $23^{\text {rd }}$ March 2017

Accepted for Publication: $31^{\text {st }}$ March 2017

Obsgyne Review: Journal of Obstetrics and Gynecology ratio (0-6 age group) is even lower i.e. 914 females / 1000 males which has fallen from 927 females / 1000 males in 2001. On comparing with this census of India and of Nashik district, it was observed that the sex ratio in Nashik is 919 but the more worrying fact is that in Nashik the Child sex ratio is 890 which is much lower than the national average of 914 [3].

This rate of decline is alarming. Various factors are associated with this low sex ratio but the major factor behind this is sex selective abortion [4]. The main reasons for this sex selective abortion is based on a common perception that female child is an economic burden on the family due to dowry problems, vulnerability of them for security reasons whereas males can prove to be a breadwinner, are strong enough to take care of their family as well as carry forward the family name.

Thus to these evil practices has lead to enforcement of Pre-conception and Pre-natal diagnostic techniques Act.

Available online at: www.medresearch.in 6| P a g e 
Original Research Article

In 1994, Government of India passed the Prenatal diagnostic techniques (Regulation and Prevention of Misuse) Act with the aim of preventing female foeticide. The implementation of this act was slow. After a few amendments it was replaced in 2002 and 2003 by the Preconception and Pre-natal diagnostic techniques (Prohibition of sex selection in any form) Act [5]. Although government is trying its best to increase the awareness of the people regarding this act, it has not been properly reflected in the practice yet with no apparent increase in the sex ratio.

Since most of the female foeticide are preventable and the PC \& PNDT act is very helpful in reducing the sex selection of the child during pregnancy and looking at the number of factors it influences and its serious implications, thorough and in depth study on the Gender preference is needed. Hence the emphasis of my study is to access the knowledge, attitude and practice related to PC \& PNDT Act amongst the women visiting ANC OPD in a tertiary care hospital in Nashik district. This is an attempt to find out the various reasons of very low child sex ratio in Nashik and also inform and educate them about PC \& PNDT Act so that this social evil of gender imbalance can be removed from the society by preventing the female foeticide because it is very important for the overall socio-economic progress of the State as well India.

\section{Aims \& objectives}

More preference towards male child and the inadequate knowledge about the PC \& PNDT acts and the lack of the harsh reality of the consequences of low sex ratio are the main reasons for undergoing sex selective abortions. Keeping all these facts in view, the study aims:

1. To assess effect of awareness programme on the Knowledge, Attitude and Practice of Gender Preference \& Pre-natal sex determination in population of Nashik district.

2 . To create awareness regarding the prevention of preconception and pre-natal sex determination (PC \& PNDT Act).

3. Contributing in the improvement of Sex ratio.

\section{Material \& Methods}

Study Design: This is a prospective Cross-sectional Study. Conducted at the ANC OPD of a tertiary care hospital over the period of two months (July - September) after getting the Institutional Ethics Committee (IEC) approval.

Sample Size: 100. Random selection

\section{Inclusion Criteria}

All female patients in the reproductive age group of 18 - 45 years up to 20weeks pregnancy, visiting ANC Clinic were included. 50\% from urban and 50\% from rural.

\section{Exclusion Criteria}

1. Women those who have completed their family.

2. Sterilized female.

3. Unmarried female.

Research Instrument: Pre-tested and validated Questionnaire (In English, Hindi and local language Marathi

Methodology- They were then informed of the survey, its objectives and procedures and assured that the information collected would be treated as confidential and used only for research purpose.

The questionnaire provided is pre-tested and pre-designed which consists of three sections: Form A, B and C

A) Questions to know the bio-social and economic status of the couple.

B) Questions to elicit the gender preference of the couple and to know their desired family size.

C) Questions to assess the knowledge, attitude and practice towards PC \& PNDT act as well as sex ratio.

Form $\mathrm{C}$ - is framed in 3 separate sections for accessing the knowledge, attitude and practice regarding PC \& PNDT act.

The variables included to evaluate the knowledge on PC \& PNDT act are, awareness regarding the law, declining sex ratio, possibility of intra uterine sex determination and methods, punishments associated with misuse of PC \& PNDT act and its extent. The attitude of antenatal women was assessed by questions like whether she will like to determine the sex of the foetus, if the sex of foetus is opposite of what they desired what will she do. The practice was assessed by questions like how will you prevent if their friend/family members wants to do in-utero sex determination? and how will they approach to such people? 
Conclusion was drawn by statistical comparison. These women were briefed about the PC \& PNDT Act and the long term consequences of the fewer females in the society.

Post filling this form, counseling of that patient was done briefing them regarding the knowledge about PC \& PNDT act, its punishment $\&$ the ill effects of the current low sex ratio, gender equality, non-decimation, women empowerment. After this counseling session, that patient was given the same form to fill and the gain in their knowledge was assessed.

Statistical Method: Data was analyzed using chi square test by using Statistical Package of Social Sciences (SPSS) 21.0 software.

\section{Observation and Result.}

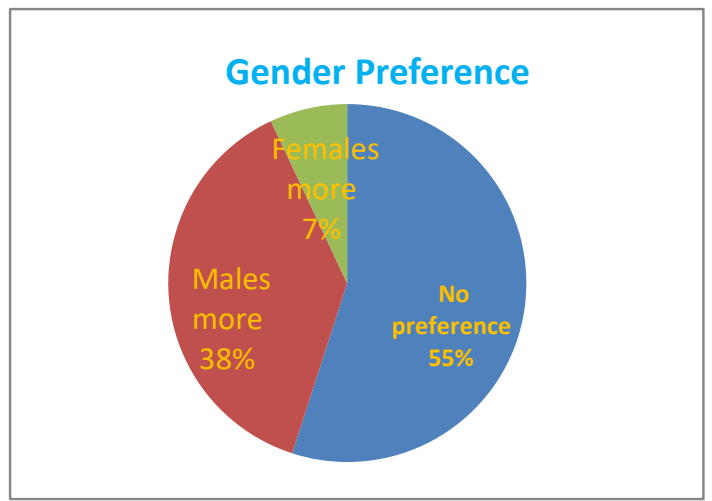

Figure-1:

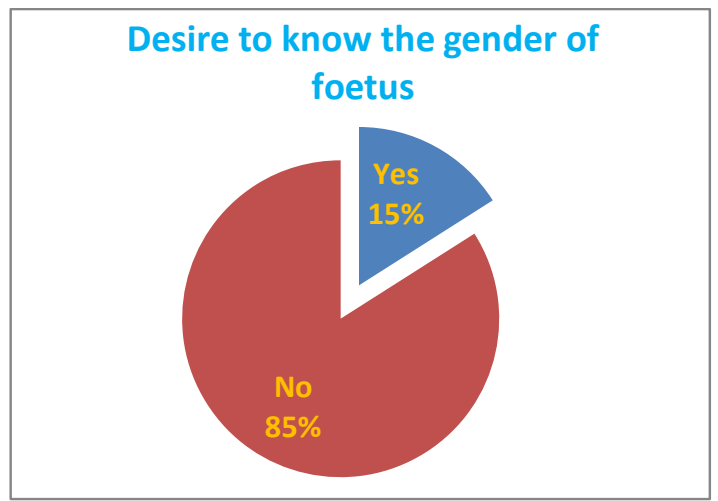

Figure-2

We observed that $15 \%$ of the population said that they desire to know the sex of the child pre-natally, and when asked regarding their knowledge about where this sex determination can be done, $28 \%$ of them said in government hospitals, $13 \%$ said it is being done in private clinics while only $22 \%$ knew correctly that it is not done anywhere now while the rest didn't had knowledge about it.

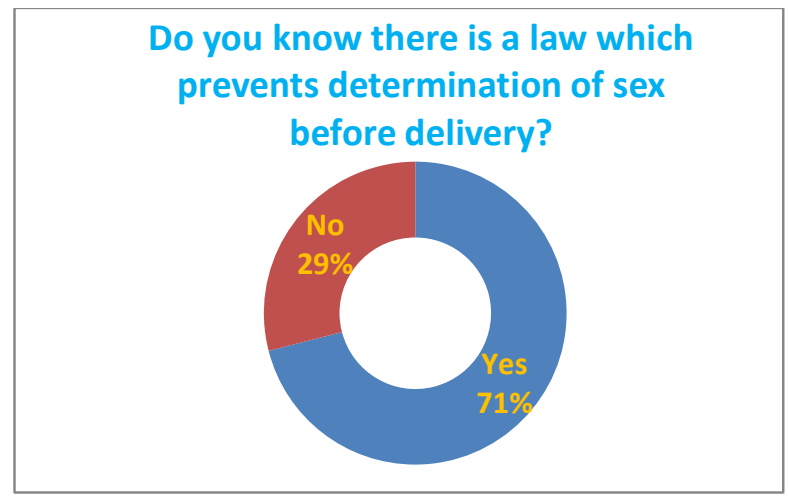

Figure-3

Table-1: Awareness Regarding the Punishment associated with the PC\&PNDT Act.

\begin{tabular}{|c|c|}
\hline \multicolumn{2}{|c|}{ Awareness Regarding the Punishment associated with the PC\&PNDT Act. } \\
\hline & Percent \\
\hline Yes & 63 \\
\hline No & 37 \\
\hline
\end{tabular}

From figure 3 and Table 1, it was known that $71 \%$ of the participants had heard about the law which makes all the pre-natal sex determination an illegal act, while $29 \%$ were not aware of it. $63 \%$ of the participants who had knowledge about the act also knew the punishment associated with it. 


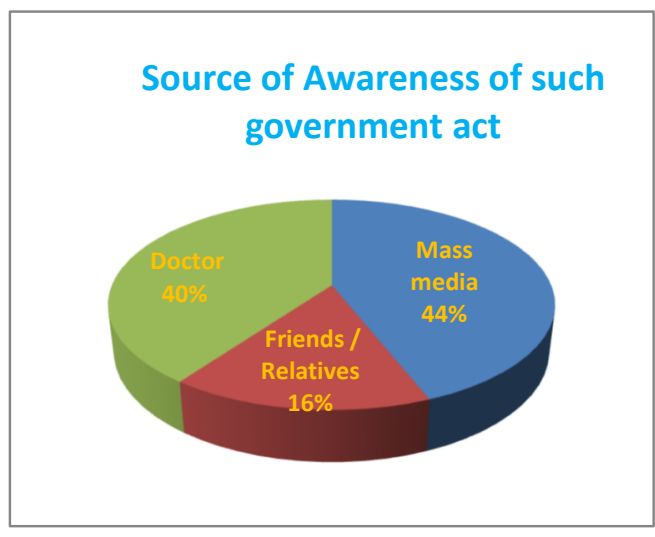

Figure-4

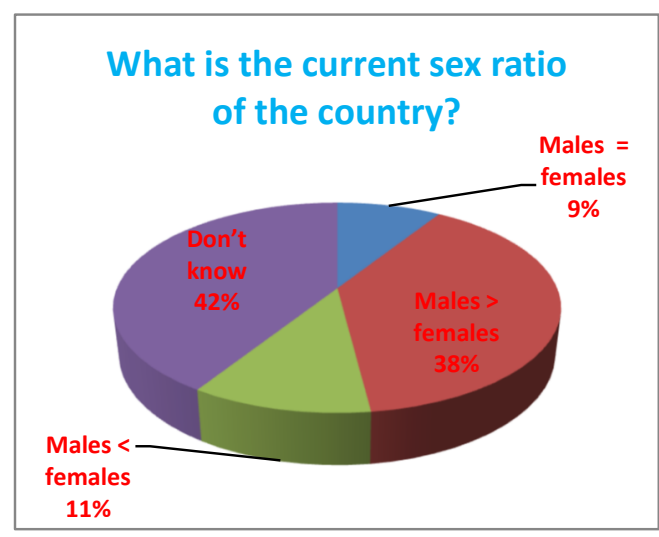

Figure-5

From figure 5, It was significantly known that only $38 \%$ of the participants had proper knowledge regarding the sex ratio of India. While $9 \%$ thought males and females are equal in number and $11 \%$ said that females are more in number in India. $42 \%$ had no idea about the sex ratio.

Table-2

\begin{tabular}{|c|c|}
\hline Will you try to increase the awareness among people ? \\
\hline & Percent \\
\hline Yes & 96 \\
\hline No & $\mathbf{1 0 0}$ \\
\hline Total & Percent \\
\hline If yes, How will you aproach to them ? & 40 \\
\hline & 47 \\
\hline By educating them & 13 \\
\hline consequences of less girls & $\mathbf{1 0 0}$ \\
\hline Both & \\
\hline Total & \\
\hline
\end{tabular}

$96 \%$ were ready to increase the awareness of the ban over sex selective determination and abortion as well as were ready to inform the governmental authorities if they find anyone undergoing sex selection. but $4 \%$ refused to do anything.

Table-3: Co-relation of Desire to know the gender of foetus and the Preference of child in family.

\begin{tabular}{|c|c|c|c|c|}
\hline \multirow{8}{*}{ Preference } & & \multicolumn{2}{|c|}{ Desire to know the gender of foetus } & \multirow[t]{2}{*}{ Total } \\
\hline & & Yes & No & \\
\hline & \multirow[t]{2}{*}{ Equal no } & 2 & 53 & 55 \\
\hline & & $3.60 \%$ & $96.40 \%$ & \\
\hline & \multirow[t]{2}{*}{ Males more } & 13 & 25 & 38 \\
\hline & & $34.20 \%$ & $65.80 \%$ & \\
\hline & \multirow[t]{2}{*}{ Females more } & 0 & 7 & 7 \\
\hline & & $0.00 \%$ & $100.00 \%$ & \\
\hline
\end{tabular}

From the above table 3, it suggested that those who had preferred more males desired to know the sex of the child during pregnancy $-34.20 \%$-- this is statistically significant $(0.000136$ i.e. $\mathbf{p}<0.05)$. 
Table-4: Co-relation of Education status with the knowledge about the sex ratio.

\begin{tabular}{|c|c|c|c|c|}
\hline \multirow{8}{*}{ Education } & & \multicolumn{2}{|c|}{ Knowledge about the sex ratio } & \multirow[t]{2}{*}{ Total } \\
\hline & & Yes & No & \\
\hline & \multirow[t]{2}{*}{ Graduate } & 16 & 5 & 21 \\
\hline & & $76.20 \%$ & $23.80 \%$ & \\
\hline & \multirow[t]{2}{*}{ Below HSC } & 19 & 47 & 66 \\
\hline & & $28.80 \%$ & $71.20 \%$ & \\
\hline & \multirow[t]{2}{*}{ Illetrate } & 3 & 10 & 13 \\
\hline & & $23.10 \%$ & $76.90 \%$ & \\
\hline
\end{tabular}

The above table shows us that, education is a very important factor. As those were graduated, $76.20 \%$ of them had knowledge about the current sex ratio of the country, while those who had studied below $12^{\text {th }}$ standard their knowledge regarding the sex ratio was below $29 \%$, which is statistically significant $-\mathbf{0 . 0 0 0 2 4 8}(\mathbf{p}<\mathbf{0 . 0 5})$

Table-5: Co-relation of Desire to know the gender of the foetus in the subsequent pregnancy with the present number of girl children in family.

\begin{tabular}{|c|c|c|c|}
\hline \multirow{2}{*}{} & \multicolumn{2}{|c|}{ Desire to know the gender of foetus } \\
\cline { 2 - 4 } & \multirow{3}{*}{ No of Girls } & Yes & No \\
\cline { 2 - 4 } & 1 & $8.90 \%$ & $91.10 \%$ \\
\cline { 2 - 4 } & 2 & $16.20 \%$ & $83.80 \%$ \\
\cline { 2 - 4 } & 3 & $50.00 \%$ & $50.00 \%$ \\
\hline
\end{tabular}

It shows that on comparing desire to know the gender of foetus in the subsequent pregnancy with the mother currently having a girl child, it was observed that after having 2 girl child $50 \%$ of them were willing to know the sex of the child during the next pregnancy, and after having 3 girl child $100 \%$ of females were willing to know the sex of child in the next pregnancy as well as could undergo abortion if by chance they get to know the sex of child during pregnancy and it was found to be a girl again. This finding is statistically significant $-0.004(p<0.05)$.

Table-6: Co-relation of Desire to know the gender of the foetus in the subsequent pregnancy with the present number of male children in family.

\begin{tabular}{|c|c|c|c|}
\hline \multirow{2}{*}{} & \multirow{2}{*}{} & \multicolumn{2}{|c|}{ Desire to know the gender of foetus } \\
\cline { 2 - 4 } & & Yes & No \\
\cline { 2 - 4 } & 0 & $16.70 \%$ & $83.30 \%$ \\
\hline \multirow{3}{*}{ No of Boys } & 1 & $5.00 \%$ & $95.00 \%$ \\
\hline & 2 & $0.00 \%$ & $100.00 \%$ \\
\hline
\end{tabular}

This table shows the finding that, after having 1 boy child, the participants did not desired to know the sex of child prenatally. While those who were not having any male child or those who were primigravid - $17 \%$ of females wanted to know the sex of child prenatally.

\section{Results of Post-Awareness programme}

- Gender Preference of a particular sex was decreased from $45 \%$ to $12 \%$.

- Desire to know the gender of foetus in the following pregnancy came down to $4 \%$ from $15 \%$

- After this awareness programme, a law which protects us from undergoing any pre-natal diagnosis for gender is banned by the government of India was known by $100 \%$ of subjects and the knowledge regarding the current sex ratio in India was also increased in all participants.

- Proper knowledge regarding PC \& PNDT Act was known by $88 \%$ participants. 


\section{Discussion}

In the present study, only $38 \%$ properly knew about the sex ratio which is very low on comparison with a study done by D Roma et al[7]. This low knowledge of the sex ratio can be the cause as most of them were less educated or illiterate. Thus education is a very important tool in such sectors.

When the respondents were asked about their awareness of PC \& PNDT act, it was found that $71 \%$ had heard about such law which was comparable with the a similar study done in Mumbai ${ }^{8}$ had knowledge about the sex ratio $>70 \%$ but a study done in Southern India showed that $91 \%$ of people had this knowledge [9] and a study done in Bikaner [10] shows that it is $52.4 \%$ and was only $11.6 \%$ in a study done at Chandigarh [5], which again shows that literacy rate is the factor for such difference.

In the present study, the majority of participants (61\%) of which $90 \%$ of people from urban area knew that ultrasonography was the technique used for sex determination, which was comparatively lower than the study done in Mumbai [8], Southern India [9] where 90\% knew about this method while a study done in Lucknow, uttar Pradesh [11] shows that 99\% subjects have knowledge regarding the sex determination methods. This might be due to factors such the place of residence, as in my study in urban area $70 \%$ knew these methods while in rural area only $52 \%$ were aware of this technique.

The reported gender preference in similar research studies in various parts of the country varies between $22.2 \%$ $69 \%[11,12,13,14]$, in the present study $38 \%$ had preferred a male child as the male child served to be the breadwinner of the family as well as carries the name of the family. The deep roots of discrimination against women and male domination can be attributed to the social system known to Patriarchy.

The major source $44 \%$ of information was through mass media followed by $40 \%$ through boards and banners at the doctors clinic the major source of information was mass media in them. A study done at meerut [14] shows that the major source of information spread is through friends and relatives. Thus it suggests that more the sources of information is provided more better will be the condition, and the social media and the emerging use of internet can be more useful in spreading such useful information in the public.

The present study also reveals that there was increasing trend of change in the attitude of the women towards the pre-natal determination of the child in those who already had a female child, and was strongly increased in those who were having 2 girl children.

This finding is statistically significant. This may be because, parents think that there is no scope of teaching a girl as it is just waste to spend so much money over them and they don't get anything in return, this was the major cause of people preferring a boy child that we came across during the progress of the research study. It has also been observed that the practice of female foeticide is more prevalent among the people residing in the urban areas as they get the easy access to misuse the technologies that have been provided to them. In rural areas the sex ratio is much more than the Nashik district area.

In present study the practice of having a large family size was observed in people having a female child and it did not affect if there is already a male child in the family. This is a statistically significant data.

\section{Conclusion}

- The existence of son preference is at an alarming high rate in our society and is the most important - the root cause of imbalanced sex ratio. Moreover, the knowledge regarding the sex ratio is very low in the population here and Education is the only tool to increase their knowledge in every sector.

- Thus Education is the important tool for increasing the knowledge of the people.

- Irrespective of the educational status or economic class, people are desiring for sex selection of the child prenatally, and majority of those already having 2 girl children could abort the next child if it is again a girl child.

- Most of the people have heard about the PC \& PNDT act that it is illegal to determine the gender of foetus, and even more than fifty percent of them had some knowledge about the punishment under the act still desired to know gender of child during pregnancy. Thus apart from the legislative measures, people also needs to be educated about the ethical issues related to female foeticide.

- Governmental schemes such as reservation for females, to provide them security are some factors which can change the attitude of the people. Women empowerment is must need in our country.

- Mass media, banners and proper advertisement, the awareness regarding PC\&PNDT act will increase as well the knowledge regarding the sex ratio and the consequences of the low sex ratio will be known to individuals. 
Acknowledgement: I sincerely acknowledge the Department of Obs-Gyne, Dept of Community medicine, CRL as well as Dean of MVP's Dr Vasantrao Pawar Medical College, Hospital and Research centre, Nashik for their help and support.

Funding: ICMR STS (Indian Council of Medical Research Short Term Studentship)

Conflict of interest: None declared

Ethical approval: The study was approved by the Institutional Ethics Committee.

\section{References}

1. Definition of the indicators of population ageing. World Population ageing 1950-2050. UNFPA (cited 2013 December 20) Available from http://www.un.org /esa/population/ publications/worldageing 19502050/pdf /95annexi.pdf.

2. Office of Registrar General and Census Commissioner, India. Population in age group 0-6 years by sex and sex ratio (0-6). Census of India, Government of India. 2011. [Last accessed on 2011 Apr 09]. Provisional population totals.Available from: http://www.censusindia.gov. in/ 2011-prov-results/indiaatglance.html .

3. Provisional Population Totals. Government of India. Census Data 2011. 19 April 2014. Retrieved 22 April 2014.

4. Implementation of PCPNDT Act in India. Perspectives and Challenges. Public Health Foundation of India. Cited November 2013) Available from http:// india.unfpa. org/drive/ implementation of the pcpndtact in indiaperspectives and Challenges.pdf.

5. Kanitkar T, Mistry M. Status of women in India - an interstate comparison. Indian J Soc Work 2000;61:381-3.

6. Handbook of PCPNDT Act and rules with amendments. Ministry of Health and Family Welfare Government of India 2006(cited 2013 October10). Available from: http:/www.iria.in /upload Notices/ Handbook_on_PNDT_Act.pdf.

\section{Original Research Article}

7. Dadwani Roma S. Tintu Thomas. "Knowledge Regarding Sex-Ratio\& PCPNDTAct". A Cross Sectional Study. International Jr. of Scientific Research vol.3 Issue8, Aug.2014, 274-276.

8. Giri P, Nagaonkar S, Shidhaye R, Shidhaye P. Study of knowledge and attitude regarding prenatal diagnostic techniques act among the pregnant women at a tertiary care teaching hospital in Mumbai. Journal of Education and Health Promotion. 2012;1(1):36.

9. Nithin K, Tanuj K, Unnikrishnan B, Rekha T, Prasanna M, Vaman K, et al. Gender preferences among antenatal women: a cross-sectional study from coastal South India. African Health Sciences. 2015;15(2):560-66.

10. Khatri M, Acharya R, Sharma G (2012) Knowledge, Attitude and Practices (KAP) Related to Pre-Conception \& Pre-Natal Diagnostic Techniques (PC \& PNDT) Act Among the Antenatal Women in Bikaner. 1: 121. doi:10. 4172/scientificreports. 121

11. Srivastava A, Singh JV, Singh OP, Singh VK, Singh N. Gender Preference, Attitude and Awareness of Young Eligible Couples towards Pre Natal Sex Determination in Lucknow District. Natl J Community Med 2014; 5(1): 148-152.

12. Christian Donald S, Sonaliya K N, Garsondiya Jignesh. Profiles, Practices and Perceptions towards Gender Preferences among Pregnant Women of Ahmedabad City, Gujarat, India.International Journal of Interdisciplinary and Multidisciplinary Studies. 2014: June; 1(6) 210-213

13. Vadera BN, Joshi UK, Unadakat SV, Yadav BS, Yadav S. Study on Knowledge, attitude and practices regarding gender preference and female foeticide among pregnant women. Indian J Community Med. 2007; 32: 300-1.

14. Kansal R, Maroof KA, Bansal R, Parashar P. A hospital-based study on knowledge, attitude and practice of pregnant women on gender preference, prenatal sex determination and female feticide. Indian J Public Health. 2010Oct-Dec;54(4):209-12.doi:10.4103/0019-557X. 77263.

\section{How to cite this article?}

Tawri P, Patole K. Effects of awareness programme on the knowledge, attitude and practice of gender preference \& pre-natal sex determination in population of Nasik district. Obs Rev:J obstet Gynecol 2017;3(1):6-12.doi: 10.17511/joog.2017.i01.02. 